\title{
COOPERATIVA NACIONAL DE PRODUCTORES DE LECHE DE URUGUAY. SU CREACIÓN ANALIZADA DESDE LAS POLÍTICAS PÚBLICAS
}

\section{NATIONAL COOPERATIVE OF DAIRY PRODUCERS. ITS CREATION IS ANALYZED FROM THE PERSPECTIVE OF PUBLIC POLICIES}

\author{
Juan Pablo Marti* \\ Universidad de la República, Montevideo, Uruguay<jpmarti@fcs.edu.uy>
}

Resumen. El artículo analiza la creación de la Cooperativa Nacional de Productores de Leche en 1935 como expresión de una política pública. En este artículo se analiza por qué se opta por una cooperativa para organizar el abastecimiento de leche en la ciudad de Montevideo, Uruguay. Se utiliza una metodología cualitativa basada en la reconstrucción de fuentes documentales y legislativas, así como historiográficas. El Estado uruguayo crea una cooperativa con un particular modelo de gestión y este se relaciona con su forma de surgimiento. En primer lugar, esto se ve reflejado en la gobernanza. Además, el origen de la cooperativa va a establecer la primacía de lo agrario sobre lo industrial y lo financiero. Finalmente, se concluye que prevalece el interés de los productores sobre el de los consumidores.

Palabras clave: cooperativas; leche; industria lechera; legislación; políticas públicas.

Abstract. The article examines the legislative creation of the National Cooperative of Dairy Producers in 1935, as an expression of public policy. The article aims at answering the question of why a cooperative is chosen to organize marketing, processing and distribution of milk in Montevideo, Uruguay. We used a qualitative methodological strategy based on reconstruction of legislative and documentary sources and review of historiographical material. The Uruguayan government created a cooperative with a particular management model and this is related to its form of emergence. First, this is reflected in the governance. Moreover, the origin of the cooperative will establish the primacy of dairy farming on industrial and financial.

\footnotetext{
* Quisiera agradecer a Raquel Pollero y Wanda Cabella, del Programa de Población de la Facultad de Ciencias Sociales de la Universidad de la República, quienes me facilitaron los datos sobre la población y la mortalidad infantil en Montevideo en la primera mitad del siglo Xx. También quisiera agradecer a Marta Silveira, de la Secretaría de la Cámara de Senadores de la República Oriental del Uruguay, quien me facilitó el acceso a las actas parlamentarias. Agradezco también a quienes en distintas etapas del trabajo me hicieron comentarios y aportes, en especial a Raúl Jacob, Carlos Demasi y Antonio Cruz, así como a los dictaminadores anónimos. Obviamente ninguno de ellos es responsable por los errores u omisiones que pudiera cometer.
}

Am. Lat. Hist. Econ., año 20, núm. 3, septiembre-diciembre, 2013, pp. 90-113 
Finally, we conclude that the interest of the dairy farmers prevails over the one of the consumers.

Key words: cooperatives; milk; dairy industry; legislation; public policies.

Fecha de recepción: junio de 2012. Fecha de aceptación: noviembre de 2012

\section{INTRODUCCIÓN}

$\mathrm{E}$

n 1935, cuando Uruguay todavía vivía los coletazos de la crisis de 1929, el parlamento uruguayo vota la creación de la Cooperativa Nacional de Productores de Leche (en adelante CONAPROLE). Por primera y única vez en la historia de este país, una ley crea una cooperativa. ${ }^{1}$ Esto constituye un hito en la historia del cooperativismo en Uruguay y suscita preguntas respecto a las condiciones que propician la aprobación de esta ley. En especial si consideramos que analizar los orígenes de las cooperativas nos permitirá avanzar en la comprensión de la estructura que adopta la organización. ${ }^{2}$ Este análisis es aún más relevante cuando constatamos una participación cada vez más activa del Estado en la creación de cooperativas. ${ }^{3}$ El estudio de los orígenes de las cooperativas nos permitirá identificar un conjunto de factores críticos para su éxito y desarrollo que, presumiblemente, obedezcan a una disposición organizativa particular, fuertemente caracterizada y condicionada por las circunstancias que contribuyeron a su creación. ${ }^{4}$

La creación por parte del Estado es una de las posibles formas de surgimiento de las cooperativas, ${ }^{5}$ y la podemos enmarcar en las políticas

${ }^{1}$ Definiremos una cooperativa como "una asociación autónoma de personas agrupadas voluntariamente para satisfacer sus necesidades económicas, sociales y culturales comunes, por medio de una empresa que se posee en conjunto y se controla democráticamente", en Alianza, Declaración, 1995. Los orígenes del cooperativismo y las mutuales en Uruguay se suelen vincular al aporte de los inmigrantes durante la segunda mitad del siglo XIX, véanse Terra, Proceso, 1984, y Bertullo et al., "Cooperativismo", 2004. Habitualmente se señalan cinco sectores cooperativos: consumo, ahorro y crédito, vivienda, producción y agropecuario. Esta segmentación es un reflejo de la división en la legislación durante todo el siglo XX.

${ }^{2}$ El trabajo se inscribe en una línea de investigación que pretende reconstruir el proceso histórico del cooperativismo en Uruguay, buscando establecer el vínculo entre las matrices de surgimiento y las modalidades de desarrollo de las cooperativas.

${ }^{3}$ Véanse al respecto Cravino y Mutuberría, "Cuando", 2010, y Martí, Soria y Dabezies, "Programas", 2008.

${ }_{4}^{4}$ Battaglia, Lorganizzazione, 2004. Coincidimos con Bustelo cuando sostiene que: "La historia económica [...] debería arrojar luz sobre el funcionamiento de la empresa a lo largo de los tiempos y extraer lecciones útiles para el presente y el futuro.” Bustelo, Historia, 1998, p. 105.

${ }_{5}^{5}$ Para analizar el surgimiento de las organizaciones cooperativas son interesantes los aportes de Vanek, Imprese, 1985, y Terra, Proceso, 1984. Una revisión de las propuestas de estos autores se puede encontrar en Camilletti et al., "Cooperativas", 2005. 
públicas, es decir, un conjunto de acciones y omisiones que manifiestan una determinada modalidad de intervención del Estado a través de sus instituciones para influir sobre una cuestión que en determinado momento los ciudadanos o el propio gobierno consideran una prioridad. ${ }^{6}$

El Estado como promotor de las cooperativas puede manifestarse de muy diversas formas. En este caso nos interesa analizar una medida legislativa a través de la cual se crea una cooperativa para organizar la comercialización, industrialización y distribución de la leche en Montevideo, capital de la República Oriental del Uruguay. ${ }^{7}$

El estudio de políticas públicas y sus impactos contiene una dimensión temporal que le es intrínseca. Por ello es posible hablar de un proceso social al analizar la trayectoria de una cuestión a partir de su surgimiento, desarrollo y eventual resolución. ${ }^{8}$

El ciclo de construcción de las políticas públicas comprende las siguientes fases: a) la identificación y definición del problema a abordar; b) la formulación de las distintas posibles alternativas de solución; c) la adopción de una alternativa entre todas las formuladas; $d$ la implantación de la alternativa seleccionada, y e) la evaluación de los resultados obtenidos. ${ }^{9}$ Todas las fases se hallan vinculadas y una alteración en cualquiera de ellas afecta a las demás, de ahí que el análisis de las políticas públicas deba llevarse a cabo con una perspectiva de globalidad e interdependencia de elementos. $^{10}$

Analizaremos la creación de la CONAPROLE, a través de la Ley 9526 del 14 de diciembre de 1935, como expresión de una política pública. ${ }^{11}$ Partiremos de la identificación de los problemas públicos que la creación de esta cooperativa pretendía resolver; exploraremos las distintas alternativas formuladas, examinaremos por qué se optó por una cooperativa,

\footnotetext{
${ }^{6}$ Varas, "Democratización”, 1997, y Tamayo Sáenz, “Análisis", 1997, p. 281.

${ }^{7}$ Además de las medidas legislativas, el Estado, a través de disposiciones fiscales, proporciona asesoramiento técnico, ayuda financiera, etcétera.

${ }^{8}$ Oszlak y O’Donnell, “Estado”, 1995, pp. 109-110. Estos autores entienden por resolución la desaparición del tema de la agenda pública sin que por ello este haya sido solucionado. En ocasiones un tema se resuelve porque otros problemas más visibles monopolizan la atención.

${ }^{9}$ Es de destacar que este proceso no se verifica en forma lineal en la realidad e incluso algunas de sus fases pueden omitirse. Se trata de un modelo útil para el análisis.

${ }^{10}$ Las política públicas son la suma o producto de iniciativas y respuestas y son diversos los organismos estatales involucrados, por ello las medidas o decisiones pueden resultar inconsistentes o conflictivas entre sí, por lo que suele hablarse de conflicto de políticas. Oszlak y O’Donnell, "Estado", 1995, p. 113.

${ }^{11}$ Una revisión de la legislación uruguaya para el fomento de cooperativas se puede consultar en Martí, "Legislación", 2011.
} 
describiremos la implementación de esta y, finalmente, evaluaremos la solución adoptada. ${ }^{12}$

Fundamentalmente, nos interesa responder a la pregunta de por qué se optó por una cooperativa para organizar la comercialización, industrialización y distribución de la leche en la ciudad de Montevideo. Y, por otra parte, en qué medida la forma de organización adoptada responde a las razones que le dieron origen.

A estas interrogantes se les suman otras motivaciones. El caso de la CONAPROLE es particularmente interesante en términos de la creación de cooperativas desde el Estado, puesto que además de ser la única creada por ley, es la más importante de Uruguay. A esto se suma que la CONAPROLE ha sido la mayor empresa láctea del país a lo largo de toda su historia ${ }^{13}$ y la principal empresa exportadora del país durante largos periodos. ${ }^{14}$

La importancia de la CONAPROLE, tanto en términos empresariales como de su particular calidad cooperativa, dieron lugar a diversos estudios desde diferentes ámbitos disciplinarios: sociológico, ${ }^{15}$ económico ${ }^{16}$ y de la historia económica. ${ }^{17}$ En tanto organismo creado por ley también se ha estudiado desde el derecho. ${ }^{18}$ Sin embargo, desde la perspectiva del cooperativismo no se han realizado análisis exhaustivos que permitan comprender más cabalmente su singularidad. ${ }^{19}$

En cuanto a la metodología, el estudio tuvo una finalidad descriptiva en tanto se propuso dar cuenta, en términos históricos, del surgimiento de la CONAPROLE como un caso de cooperativa impulsada por la acción estatal. La investigación fue también de tipo explicativa, ya que no sólo aspiraba dar a conocer el origen de la organización, sino que, a partir de ello, entender y explicar las relaciones entre sus condiciones de surgimiento y las soluciones adoptadas. Para la recolección de información se recurrió a la reconstrucción de fuentes documentales y legislativas y de fuentes historiográficas.

${ }^{12}$ Un mayor desarrollo sobre el ciclo de las políticas públicas aplicadas al cooperativismo en Uruguay se puede encontrar en Martí, Soria y Dabezies, "Programas", 2008.

${ }^{13}$ En 2012, la ConAPROLE captó 65\% de la leche remitida a la industria. Instituto, "Informe", 2012, p. 11.

${ }_{14}$ En 2011, la CONAPROLE fue la principal empresa exportadora uruguaya. Uruguay, "Informe", 2012, p. 7.

${ }^{15}$ Véanse Supervielle, CONAPROLE, 1986, y Robertt, "Restructuraçao", 2006.

${ }^{16}$ Véanse Sosa, CONAPROLE, 1986.

${ }^{17}$ Aunque estos en el marco del desarrollo de la industria lechera. Véanse Jacob, Uruguay, 1981; Bértola, Industria, 1991, y Bertino y Tajam, "Agroindustria”, 2000.

${ }^{18}$ Véanse Durán, Naturaleza, 2003, y Reyes, "Antecedentes", 2009.

${ }^{19}$ Terra, Proceso, 1984, realiza uno de los análisis más completos sobre la CONAProle desde la perspectiva del cooperativismo. 
Además de esta introducción, en este artículo se estudia la creación de la CONAPROLE, además de discutir los resultados y proponer algunas conclusiones.

\section{ANÁLISIS DE LA CREACIÓN DE LA CONAPROLE}

La CONAPROLE fue creada por la Ley 9526 del 14 de diciembre de 1935. El objetivo era organizar la comercialización, industrialización y distribución de la leche en Montevideo. Analizaremos el ciclo de las políticas públicas en las distintas etapas de la creación de esta. Intentaremos contestar las siguientes preguntas: $a$ ) ¿a qué problema se quiere responder con la creación de la CONAPROLE?; b) ¿cuáles fueron las distintas alternativas de solución formuladas en su momento?; c) ¿ por qué se adopta como alternativa la creación de una cooperativa de productores lecheros?; d) ¿cómo se lleva adelante tal iniciativa?, y e) ¿cuáles fueron los resultados evaluados desde el problema que se busca solucionar?

\section{Los problemas identificados}

Como ninguna sociedad está en condiciones de atender todas las necesidades y demandas de sus integrantes, sólo algunas cuestiones -problemas, necesidades o demandas sociales- logran ser socialmente problematizadas. ${ }^{20}$ En este caso, la cuestión socialmente problematizada es el abastecimiento de leche a la ciudad de Montevideo, que se encontraba en crisis desde comienzos del siglo XX. A comienzos de la década de 1930 el abasto de leche estaba siendo afectado por la competencia entre las plantas procesadoras, los bajos precios que recibían los productores, la mala calidad de la leche, que no superaba las inspecciones municipales, y controles que no se realizaban o no se hacían correctamente.

$\mathrm{El}$ análisis del contexto de la época y la discusión parlamentaria que precede a la creación de esta cooperativa muestran la concurrencia de dos situaciones que contribuyen a poner el tema en la agenda pública. En primer lugar, una cuestión de salud pública generada por la mala calidad de la leche y sus consecuencias, que en la discusión parlamentaria se plan-

\footnotetext{
${ }^{20}$ Problematizadas en el sentido de que ciertos grupos, organizaciones o individuos creen que puede y debe hacerse algo al respecto y promueven su incorporación a la agenda de problemas socialmente vigentes. Oszlak y O’Donnell, "Estado”, 1995, p. 110.
} 
teaba como "el problema higiénico de la leche". ${ }^{21}$ La segunda situación es la que se daba en llamar el "problema lechero".

La mala calidad de la leche se relacionaba directamente con la problemática de la salud de Montevideo y se reflejaba en la mortalidad infantil. ${ }^{22}$ Las principales causas de mortalidad infantil en la ciudad durante casi toda la primera mitad del siglo Xx fueron las diarreas y las enfermedades localizadas en el aparato respiratorio. ${ }^{23}$ Esto tiene relación con la creación de la ConAProle, puesto que una de las principales causas de enfermedades gastrointestinales era la infección transmitida por el agua y los alimentos, especialmente la leche, al tratarse de un alimento de amplia difusión entre la sociedad uruguaya. ${ }^{24}$

La leche consumida en Montevideo a comienzos del siglo Xx no era de buena calidad; $65 \%$ de la que se consumía en la ciudad en $1913^{25}$ provenía de establecimientos rurales llamados tambos. ${ }^{26}$ En el Congreso de la Leche, realizado en 1918, el doctor Morquio sostenía que la leche proveniente de las lecherías rurales era toda de mala calidad, extraída y envasada en condiciones defectuosas, sin respetar reglas de higiene y llegaba a las familias muchas horas después del ordeñe. ${ }^{27}$ Por su parte, otro de los especialistas

${ }^{21}$ Informes mencionados por el diputado Estol señalaban que la leche consumida por los enfermos de la Asistencia Pública tenía más de 20000000 de microbios por centímetro cúbico. Diario de Sesiones de la Cámara de Representantes, 6 de noviembre de 1935, p. 37.

${ }^{22}$ Se entiende la mortalidad infantil como la muerte de los niños ocurrida entre el nacimiento y el primer año de vida.

${ }^{23}$ Birn, Cabella y Pollero, "Estancamiento", 2005, pp. 137-154. En términos relativos la sumatoria de estas dos causas representó entre 45 y $65 \%$ de la mortalidad infantil por causa definida, véase Birn, Cabella y Pollero, "Enigma", 2006. Las mismas autoras sostienen que "las enfermedades gastrointestinales fueron la principal causa de muerte en los niños menores de un año hasta mediados del siglo XX, en Birn, Cabella y Pollero, "Estancamiento", 2005, p. 143. Véase también Pellegrino et al., "Transición", 2008.

${ }^{24}$ Otra de las causas de la mortalidad infantil se relacionaba con el "efecto urbano". La rápida urbanización de Montevideo, particularmente en el primer tercio del siglo Xx, implicó el deterioro de las condiciones sanitarias, de vivienda y hacinamiento de sus habitantes. Birn, Cabella y Pollero, "Estancamiento", 2005, p. 140.

${ }^{25}$ Bertino y Tajam, "Agroindustria”, 2000, p. 2.

${ }^{26}$ En Argentina y Uruguay se utiliza el término tambo (del quechua tampu) para designar a los establecimientos ganaderos destinados al ordeñe de vacas y a la venta, generalmente al por mayor, de su leche. El tambo, generalmente, está compuesto por un conjunto de espacios e infraestructuras entre las que se encuentran campos donde pasta el ganado, el tambo propiamente dicho, o espacio donde se realiza el ordeñe de las vacas, y las instalaciones para el almacenamiento temporal de la leche y su posterior remisión a las fábricas procesadoras.

${ }^{27}$ Luis Morquio, "Leche de vaca para niños", Revista Médica del Uruguay, año 21, núm. 3, 1918, pp. 97-118, en Birn, Cabella y Pollero, "Infant", 2010. Luis Morquio, fundador de la pediatría uruguaya y del Instituto Internacional Americano de Protección a la Infancia en 1927, recomendaba el consumo de leche proveniente de los tambos de la ciudad y su inmediata ebullición. Hace notar además que la leche de las lecherías rurales era consumida por los niños más pobres y los sectores altos pudientes consumían la leche de los tambos de la ciudad. Birn, Cabella y Pollero, "Estancamiento", 2005, p. 145. 
de la época, L'Harpe, sostenía que no había refrigeración ni en los tambos ni en los vagones que trasladaban la leche. ${ }^{28}$

Además del "problema higiénico de la leche", la otra cuestión que se quería solucionar era el llamado "problema lechero". El ministro de Ganadería de la época lo exponía ante la Cámara de Representantes de la siguiente manera: "es la situación de 1300 tambos que proveen leche a la capital; es la situación de 10000000 de pesos entregados a esta industria, y de más de 13000 personas que están viviendo desde hace meses este contrasentido económico: de ver perecer sus energías y capital, entregados a la acción creadora de la producción". ${ }^{29}$

La leche para abastecer a Montevideo provenía de la denominada "cuenca lechera". Esta cuenca, como resultado del desarrollo de los medios de transporte y de la presión a los productores por el encarecimiento de los arriendos, se había ido alejando de la ciudad y ocupaba un radio de 130 kilómetros (mapa 1). ${ }^{30}$

Los tambos de la cuenca lechera de Montevideo presentaban diversos inconvenientes, de acuerdo con el Censo Agropecuario de 1937:

Los altos arrendamientos, exceso de mano de obra, falta de pastoreo suficiente o mala calidad del mismo representan también factores que, unidos a los precitados [mala calidad del ganado, no producción de forraje y falta de rentabilidad del capital invertido], constituyen las caudas que determinan, en la generalidad de los casos, el fracaso de las explotaciones lecheras. ${ }^{31}$

En consecuencia, los productores se enfrentaban a una demanda concentrada, debían pagar altos precios por el arrendamiento de las tierras, contaban con una tecnología atrasada, tenían ganado de mala calidad y pasturas con fuertes variaciones estacionales. ${ }^{32}$ A esto deben agregarse problemas relativos al transporte -lentitud y falta de vagones termos- y al propio mercado de la leche. El mismo Censo Agropecuario de 1937 sostenía:

El florecimiento de la industria lechera no fue todo lo importante que se esperaba, debido en parte a la falta de una organización adecuada de los mercados de consumo, en particular de los internos, haciéndose en determinados momentos difícil la

${ }^{28}$ L'Harpe, Compendio, Montevideo, 1934, citado en Bertino y Tajam, "Agroindustria”, 2000.

${ }^{29}$ Diario de Sesiones de la Cámara de Representantes, 29 de octubre de 1935, p. 172.

${ }^{30}$ Además de Montevideo, los tambos se ubicaban en los departamentos de San José, Canelones, Florida, Maldonado y Lavalleja: "Los tambos que abastecían a Montevideo eran 1 432, de los cuales 1167 estaban fuera del departamento”, Jacob, Uruguay, 1981, pp. 219-220.

${ }^{31}$ Ibid., p. 220.

${ }^{32}$ Bértola, Industria, 1991, p. 190. 
MAPA 1. URUGUAY: MONTEVIDEO

Y SU CUENCA LECHERA (CA. 1935)

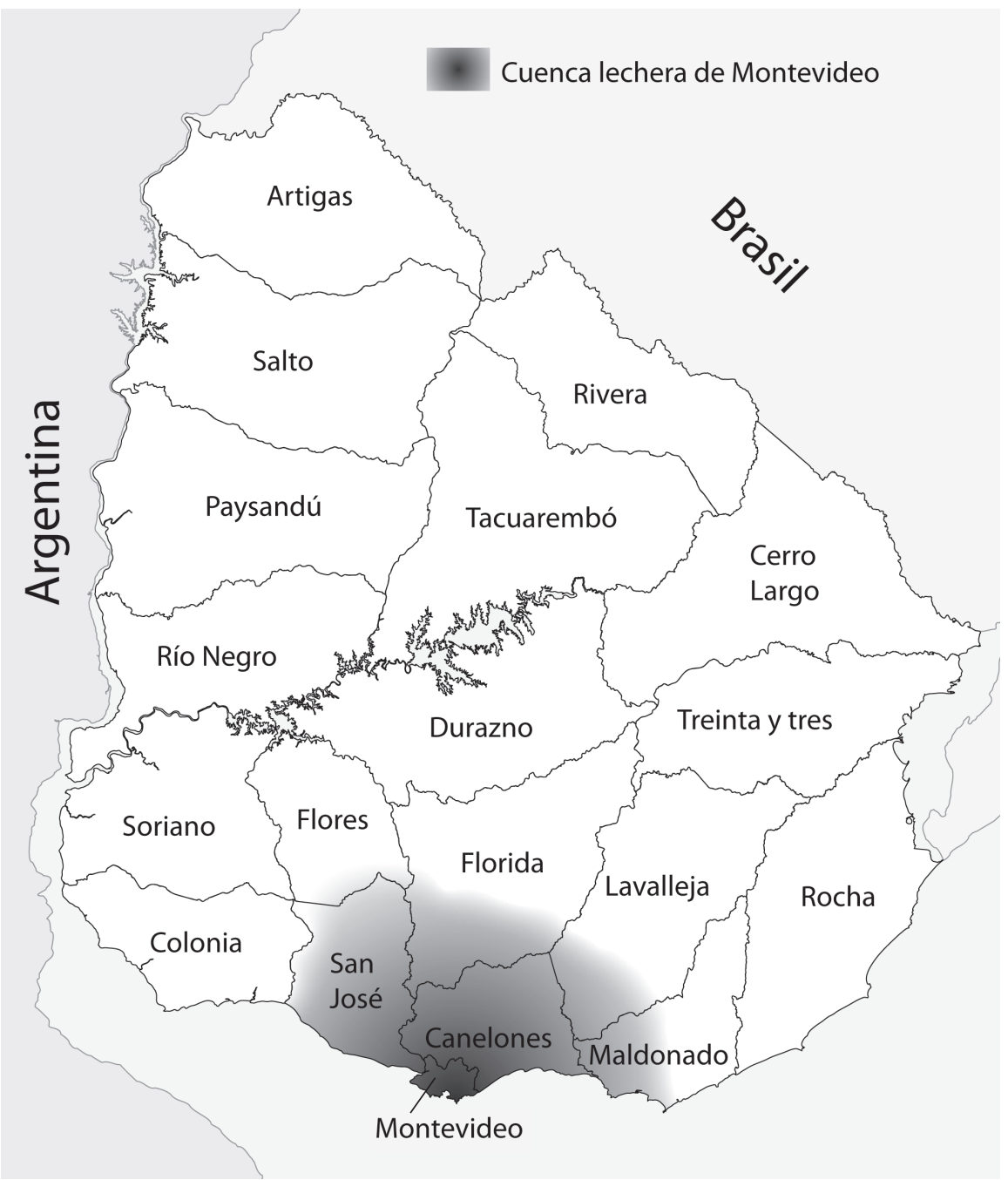

Fuentes: Elaboración propia con base en Jacob, Uruguay, 1981, y Bertino y Tajam, “Agroindustria”, 2000. 
colocación de toda la producción, y en parte a defectos técnicos y económicos en la explotación de los establecimientos productores que, además de acentuar la dificultad de colocación por la producción abundante en primavera y otoño y escasa en verano e invierno, influyen desfavorablemente en los costos de producción. ${ }^{33}$

Desde 1927, cuando se estableció la obligatoriedad de la pasteurización, se habían estado instalando plantas procesadoras de leche en Montevideo. ${ }^{34}$ Algunas de estas se originan en la fusión de granjas, y en otros casos son consecuencia de la movilización de capitales vinculados a gremialistas rurales, productores, banqueros y profesionales liberales. Durante la discusión parlamentaria previa a la creación de la CONAPROLE, el senador del Partido Colorado ${ }^{35}$ Manuel Tiscornia denunció las tendencias monopólicas de las mismas y la situación a la que sometían al productor lechero: "Es cierto que en el gremio de lecheros los productores de leche reciben una paga insuficiente." 36 Lo que motivó que se reclamara desde distintos ámbitos la intervención del Estado.

A la crítica situación de los productores, se debe agregar que las seis plantas pasteurizadoras existentes estaban en conjunto muy sobredimensionadas. El productor recibía bajos precios por la leche remitida y el consumo quedaba mal abastecido en invierno, las plantas estaban en bancarrota y los pagos a los productores se hacían con retraso. ${ }^{37}$

La discusión parlamentaria que precedió a la CONAPROLE mostró que el "problema higiénico de la leche" aparecía como el primero socialmente problematizado; ${ }^{38}$ aunque era tanto o más importante el peligro de la explosión del "problema lechero" que visualizaban los legisladores. ${ }^{39}$

${ }^{33}$ En Jacob, Uruguay, 1981, p. 221.

${ }^{34}$ Ibid., pp. 222-223.

${ }^{35}$ El Partido Colorado y el Partido Nacional tienen su origen en el siglo XIX. Al Partido Colorado se lo identifica con las posturas más liberales. Sin embargo, a comienzos del siglo XX, y con la presidencia de José Batlle y Ordóñez (1856-1929), el batllismo, sector liderado por dicho presidente y mayoritario dentro del partido, impulsó políticas liberales en lo político e intervencionistas en lo económico. Sus posturas anticlericales y las políticas de intervención estatal en la economía y de legislación social de avanzada, le valieron el enfrentamiento con los sectores conservadores de su partido y de la oposición. Dentro del mismo Partido Colorado algunos sectores conservadores, particularmente el denominado riverismo, van a cuestionar la intervención del Estado propugnada por el batllismo y apoyarán el golpe de Estado de Terra.

${ }_{36}$ Diario de Sesiones de la Cámara de Senadores, 14 de diciembre de 1935, p. 359.

${ }^{37}$ Terra, Proceso, 1984, p. 127.

${ }^{38}$ En una entrevista realizada en 1998 el gerente de producción de la CONAPROLE manifestaba que la creación de la cooperativa fue para solucionar el problema de mala calidad de la leche. Frente a la pregunta sobre el origen de la cooperativa explicaba: "El tema también pasaba por [...] una serie de factores que llevaron a que realmente [los problemas de] la calidad de la leche y aun su valor nutritivo y sobre todo libre de contaminación bacteriológica fueran muy grandes." Taramasco et al., "Estudio", 1997, p. 1.

${ }^{39}$ Decía el diputado Wilson: "es imperioso y urgente resolver de una vez este viejo problema [el lechero] siempre aplazado en su faz fundamental”. Diario de Sesiones de la Cámara de Representantes, 6 de noviembre de 1935, p. 35. 


\section{Formulación de alternativas}

Previo a la creación de la CONAPROLE se ensayaron desde el Estado distintas medidas, como la fijación del precio de la leche o la limitación de la cantidad de usinas en Montevideo. ${ }^{40}$ Pero es la pasteurización lo que más preocupaba a las autoridades de la época. En 1925 se instaló la primera empresa pasteurizadora, la Lechería Central Uruguaya Kasdorf, S. A., y en 1927 fue reglamentada su actividad. Posteriormente, en 1930, se fundó la Cooperativa de Leche, S. A., cuando ya la pasteurización era obligatoria. ${ }^{41}$ Pero apenas el 25 de abril de 1933 se decretó que la municipalidad de Montevideo "pondrá en vigencia de inmediato la ordenanza sobre pasteurización de la leche".

Una ley aprobada en diciembre de 1929 insistió en el tema y estableció que a partir del 1 de enero de 1934 se debía hacer efectiva la ordenanza sobre la pasteurización de la leche. ${ }^{42}$ Sin embargo, tal como lo manifiesta L'Harpe, aunque se efectivizara el cumplimiento de esta resolución, la pasteurización no era la solución: "Si cuando la leche llega a la usina higienizadora está cargada de microbios y contiene impurezas como la mayor parte de la que llega a Montevideo, ya es leche en condiciones deficientes para no decir mala; la pasteurización no hace más que detener el momento en que se echará a perder del todo." ${ }^{43}$

Además, al no ser compulsiva la pasteurización, algunos productores que invirtieron en la misma debieron competir con el precio inferior de la leche cruda. Esto obligaba a tomar el asunto de la producción de la leche y su procesamiento en conjunto. Otro intento de solución es el referido a la limitación de los tambos, repartidores, despachos y usinas que abastecían a Montevideo, resuelta en 1934 por la municipalidad, pero que no corrigió la desproporción de lo que recibía el productor. ${ }^{44}$ Posteriormente se intentó la fijación del precio. La Ley 9462 fijaba el precio de la leche al productor, las contribuciones, el costo de pasteurización y el precio final al consumidor, además de ratificar las limitaciones en cuanto al número de usinas establecidas por la Municipalidad de Montevideo. ${ }^{45}$

\footnotetext{
${ }^{40}$ La Ley 9462 del 7 de febrero de 1935 limita el número de usinas procesadora de leche y fija los precios de venta y compra. Aunque, a juicio de los actores sociales de la época, esta ley no tuvo los efectos deseados.

${ }^{41}$ Terra, Proceso, 1984, p. 127.

${ }^{42}$ Jacob, Uruguay, 1981, pp. 223 y 224.

${ }^{43}$ L'Harpe, Compendio, 1934, en Bertino y Tajam, “Agroindustria”, 2000, p. 15.

${ }^{44}$ Jacob, Uruguay, 1981, p. 225.

${ }_{45}$ Bertino y Tajam, "Agroindustria”, 2000, p. 21.
} 
Otra de las propuestas, formulada por el Partido Nacional, ${ }^{46}$ planteaba la exoneración impositiva como forma de ayudar a la industria lechera. "La Agrupación Parlamentaria del Partido Nacional expresa su voluntad de prestar apoyo efectivo a la industria lechera mediante la total exoneración de patentes de giro y rodados, contribución inmobiliaria y demás impuestos." ${ }^{47}$

Finalmente, la posibilidad de formación de una cooperativa se presentó como una de las soluciones posibles. Por una parte, se entroncaba con el reclamo por la organización de la lechería en cooperativas a comienzos del siglo Xx: cooperativas lácteas que protegieran a los productores, eliminaran a los intermediarios y controlaran la calidad. ${ }^{48}$ Además, la solución cooperativa contaba con profusos antecedentes, aunque muchos de ellos no llegaron a concretarse. ${ }^{49}$

Un proyecto presentado en 1934 por el diputado nacionalista Arturo Wilson iba en el mismo sentido. Planteaba la intervención del Estado centralizando la industrialización de la leche y la constitución de una cooperativa nacional de lecherías y venta de productos de granja. ${ }^{50}$

\section{Adopción de una alternativa}

La opción por la creación de una cooperativa de productores no se explica sin la intervención de la Asociación Nacional de Productores de Leche..$^{51}$ A esto se sumaba el apoyo estatal (el Banco de la República Oriental del Uruguay ${ }^{52}$ y la Municipalidad de Montevideo) y de otras entidades gremiales rurales (Asociación y Federación Rural). Con la cooperativa se

${ }^{46}$ El Partido Nacional (o Blanco) es uno de los partidos políticos tradicionales de Uruguay. Su fundación se remonta al siglo XIX y su ideología se identifica con posturas nacionalistas y la oposición al batllismo y sus políticas estatistas.

${ }^{47}$ Ingeniero Césareo Alonso Montaño, citado por Jacob, Uruguay, 1981, p. 225.

${ }^{48}$ Bertino y Tajam, "Agroindustria", 2000, p. 17.

${ }^{49}$ Entre otras iniciativas de años anteriores destacamos: la creación de las Estaciones Agronómicas de Paysandú y Salto con usinas cooperativas (1926); la escuela de lechería en Colonia con contribución de la Sociedad de Fomento Rural (1926); la instalación de la S. A. Cooperativas de Lecherías que agrupaba a 400 proveedores de leche de Montevideo (1928); la escuela agronómica de Cerro Largo con instalación frigorífica para uso de los productores (1929), y las escuelas industriales con usinas de pasteurización de leche para la enseñanza y como base de cooperativas de lechería (1930). Ibid., pp. 17-18.

${ }^{50} \mathrm{Jacob}$, Uruguay, 1981, p. 224. Arturo Wilson participará también en la comisión que formulará el proyecto de creación de la Conaprole. Diario de Sesiones de la Cámara de Representantes, 29 de octubre de 1935, p. 172.

${ }^{51}$ La Asociación Nacional de Productores de Leche fue fundada el 23 de abril de 1933 para la agremiación y defensa de los productores lecheros.

${ }_{52}$ El Banco de la República Oriental del Uruguay fue creado en 1896 y está conformado exclusivamente con capitales estatales. 
esperaba la creación de un mercado de consumo interno de leche que permitiría a los productores hacer frente a los costos de producción, encarar las oscilaciones de la producción marcadas por la escasez en invierno y la sobreproducción en verano, y asegurase la calidad del producto. ${ }^{53}$

Dentro del gobierno, el proyecto contó con el apoyo de los sectores conservadores opuestos al estatismo del batllismo y que alentaron el golpe de Estado en marzo de $1933 .^{54} \mathrm{El}$ diputado Almada sostuvo durante la discusión del proyecto de ley que "el movimiento revolucionario del 31 de marzo obedeció [...] a la razón económica de reaccionar contra la hipertrofia del Estado manifestada en intromisiones indebidas en las actividades privadas". ${ }^{55}$

La solución cooperativa iba en línea con el pensamiento del terrismo ${ }^{56}$ el ministro de Ganadería y Agricultura, César G. Gutiérrez, en la sesión del 29 de octubre de 1935, sostenía: "El cooperativismo permite unir los dos extremos [capitalismo y estatismo]: la actividad inteligente y administrativamente celosa del capitalismo, que reclamaba para sí los provechos de la industria, con la distribución generosa y justa de los rendimientos de la colectividad." ${ }^{57}$

Por otra parte, la organización de cooperativas, como vimos, venía planteándose desde principio de siglo como solución al "problema lechero". Formaba parte del programa batllista, especialmente de los sectores más moderados, que enfrentaban la doctrina de la expansión del Estado en la economía. En particular, el presidente Gabriel Terra era partidario de formar cooperativas para la mayor parte de las actividades. ${ }^{58}$

La opción no era por cualquier cooperativa sino, como argumentó el ministro de Ganadería y Agricultura, se creaba una régie cooperative: ${ }^{59}$ "dentro del cooperativismo hemos elegido la fórmula de la régie cooperative; aquella que ha surgido en Bélgica en el año 1869 con la Régie Cooperative

53 Robertt, "Reestruturação", 2006, p. 106.

${ }^{54}$ Jacob, Uruguay, 1981, p. 226.

${ }_{55}$ Diario de Sesiones de la Cámara de Representantes, 6 de noviembre de 1935, p. 40.

${ }^{56}$ Hace referencia al movimiento liderado por Gabriel Terra (1873-1942). Terra fue presidente constitucional de Uruguay entre el 1 de marzo de 1930 y el 31 de marzo de 1933. En esta fecha dará un golpe de Estado apoyado por sectores conservadores opuestos a las políticas estatizadoras del batllismo. El 19 de abril de 1934 se plebiscita la nueva Constitución y se elige la fórmula presidencial Terra-Navarro para el periodo de gobierno 1934-1938. Las elecciones tuvieron una alta abstención y en el parlamento estuvieron representados exclusivamente los que participaron de dicha elección: terristas, riveristas y colorados tradicionalistas (Partido Colorado), herreristas (Partido Nacional) y una representación muy minoritaria de cívicos (social-cristianos), socialistas y comunistas. Los sectores batllistas (Partido Colorado) y nacionalistas independientes y blancos radicales (Partido Nacional) se abstuvieron. Jacob, Uruguay, 1983, pp. 58 y ss.

${ }^{57}$ Diario de Sesiones de la Cámara de Representantes, 29 de octubre de 1935, p. 175.

${ }^{58}$ En 1920, siendo Terra ministro del Interior, presentó un proyecto de ley para la creación de un Instituto Nacional Cooperativo. Vicens, Régimen, 1941, p. 176.

${ }^{59}$ La idea de la régie cooperative fue desarrollada en Lavergne, Socialisme, 1955. 
de Crédits y que desde ese primer ensayo, puede decirse que no ha registrado ningún fracaso". ${ }^{60}$

El propio ministro abundaba en detalles y sostenía que se trataba de una régie cooperative puesto que nacía de una ley y serían solamente los productores los que tendrían la dirección de la misma, el Estado no intervendría en la administración y renunciaba a toda intromisión que no fuera la de un síndico designado por el Banco de la República Oriental del Uruguay. ${ }^{61}$

Una vez adoptada la figura cooperativa, el tema que restaba resolver para la implementación era la creación de un monopolio. La discusión respecto a este punto llevó buena parte del debate parlamentario. Estaban las posiciones de aquellos que se oponían abiertamente al monopolio y que rechazaban la intervención del Estado en la economía, como el senador Tiscornia, que argumentaba: "En el orden general soy enemigo de los monopolios. Me parece que sustraer cualquier riqueza al juego regular de la oferta y de la demanda es crear situaciones que impidan el desenvolvimiento debido, o que se presten a absorciones que hieran la riqueza misma." ${ }^{62}$

Otras posturas, si bien eran críticas al proyecto y al intervencionismo estatal, admitían la creación del monopolio al no tratarse de uno estatal y suplantar uno de hecho, ${ }^{63}$ tal como argumentaba Luis Alberto de Herrera. ${ }^{64}$ También existían posturas más críticas al monopolio y en particular a uno de este tipo, puesto que la creación de la CONAPROLE, tal como argumentaba el diputado Magnoni, implicaba:

la suma total, [que] puede ser calculada en 1300000 pesos, [...] es lo que le va a costar a las clases pobres trabajadoras más necesitadas este proyecto, que sólo ha sido hecho en vista de la protección al sector que debía haber sido menos contemplado en este problema de la leche, del sector que está respaldado por la posibilidad económica más firme y para salvar los grandes capitales invertidos en las suntuosas usinas de pasteurización en detrimento de la población consumidora. ${ }^{65}$

${ }^{60}$ Diario de Sesiones de la Cámara de Representantes, 29 de octubre de 1935, p. 175.

${ }^{61}$ El carácter de régie cooperative de la CONAPROLE, si bien generalmente aceptado, también ha sido discutido y puesto en cuestión. Véase Martí, "Cooperativas”, 2011.

${ }^{62}$ Diario de Sesiones de la Cámara de Senadores, diciembre de 1935, p. 259.

${ }^{63}$ Luis Alberto de Herrera (1873-1959), líder de la fracción conservadora del Partido Nacional. Su conducción se caracterizó por la oposición al batllismo, lo que lo llevó a apoyar el golpe de Estado de Terra en 1931 y participar de las elecciones del año siguiente.

${ }^{64}$ Jacob, Uruguay, 1981, p. 230.

${ }_{65}$ Diario de Sesiones de la Cámara de Representantes, 29 de octubre de 1935, p. 177. El diputado Magnoni fue miembro informante en minoría de la Comisión de Fomento de la Producción. 
La oposición parlamentaria también criticó otros aspectos del proyecto presentado. Por ejemplo, el carácter no cooperativo de la institución que se creaba. En este sentido, el diputado socialista Troitiño apoyaba la figura cooperativa, pero cuestionó el carácter no democrático del proyecto

Nosotros somos grandes partidarios del cooperativismo [...]; el cooperativismo es la mejor escuela para los trabajadores que aspiran a suprimir los privilegios y a emanciparse del yugo capitalista. [...] Los productores tendrán por este proyecto de ley -y por eso decía que no es un proyecto de cooperativa auténtica- el derecho de elegir, y casi nada más que ese derecho; porque luego se les da [...] un predominio a los productores más ricos, adjudicándoseles una mayor cantidad de votos. ${ }^{66}$

También se criticó que la expropiación de las plantas existentes en el momento significaba el salvataje de las usinas pasteurizadoras. ${ }^{67}$ Se expropiaba las empresas cuando sus acciones estaban a la mitad de su valor. ${ }^{68}$

Por último, otra de las críticas más fuertes apuntaba al aumento del precio de la leche, que favorecía a los productores, perjudicando a los distribuidores y recaía sobre el consumidor. ${ }^{69} \mathrm{Al}$ respecto, el citado diputado Líber Troitiño sostenía: "El proyecto del poder ejecutivo [...] trata de favorecer [...] el interés de los productores del campo, pero sacrifica inmediatamente el interés de los distribuidores de leche; próximamente el interés de los empleados y obreros de las usinas que se dedican a esta industria, y, también inmediatamente, al gran interés de la gran masa de consumidores de leche."70

Finalmente el proyecto fue aprobado con los votos del oficialismo y el voto negativo de comunistas, cívicos y socialistas basándose en las críticas antes mencionadas. ${ }^{71}$

${ }^{66}$ Ibid., p. 179.

${ }^{67}$ Distintas voces se levantaron en este sentido en el debate realizado en la Cámara de Representantes. El diputado del Partido Colorado Dupont Aguiar sostuvo: "en el fondo lo único que busca solucionar es el problema de los grandes accionistas, de las grandes usinas". Diario de Sesiones de la Cámara de Representantes, 6 de noviembre de 1935, p. 34. En la misma dirección se expresaba el diputado socialista E. Frugoni, quien decía: "soy un convencido que se trata de una operación de salvataje, no precisamente de los productores auténticos, sino de los accionistas de las grandes compañías". Diario de Sesiones de la Cámara de Representantes, 6 de noviembre de 1935, p. 42.

${ }^{68} \mathrm{Jacob}$, Uruguay, 1981, p. 232. Incluso se mencionaron las implicancias del ministro Gutiérrez, propietario de acciones de una de las usinas a ser expropiadas.

${ }^{69}$ El diputado Magnoni calcula en 423.00 pesos anuales el sobreprecio que recaería sobre el consumidor. Diario de Sesiones de la Cámara de Representantes, 29 de octubre de 1935, p. 177.

${ }^{70}$ Ibid.

${ }^{71}$ Jacob, Uruguay, 1981, p. 233. 


\section{La implementación}

El 14 de diciembre de 1935 la Ley 9526 creó la CONAPROLE. En la misma se establecía: "Toda la leche destinada al consumo de la población de Montevideo, que no reúna las condiciones exigidas por las ordenanzas respectivas para el expendio de leche cruda, será higienizada y pasteurizada en la o las usinas de la [CONAPROLE]. La CNPL explotará, bajo el indicado régimen de libre concurrencia, las distintas ramas de la industria lechera y sus derivados." 72

Al crear la CONAPROLE, el Estado uruguayo se proponía la formación de un mercado interno y garantizar el consumo de un producto saludable. Es por ello que se dispuso: "Todo productor de leche, de cualquier zona del país, podrá hacerse miembro de la CNPL, remitiéndole su producción." ${ }^{73}$

La creación se hizo a través de la expropiación y fusión de varias plantas procesadoras de leche. Los activos fueron adquiridos por el Estado uruguayo y luego traspasados a la CONAPROLE, quien asumió la deuda. ${ }^{74}$ La planta industrial de la CONAPROLE se instaló en los locales de la antigua Lechería Central Uruguaya Kasdorf, S. A. Además de las instalaciones, se incorporaron sus trabajadores, sus marcas e incluso sus patentes. ${ }^{75}$

La intervención del Estado en la creación de la cooperativa era muy amplia. La ley establecía que la CONAPROLE fuera dirigida por un directorio compuesto de cinco titulares y diez suplentes, elegidos por los productores que tuvieran al menos un año de antigüedad. ${ }^{76}$ La elección del directorio sería instrumentada por la corte electoral. A diferencia de la concepción democrática establecida por los principios históricos del cooperativismo de un hombre-un voto, la ley ponderaba el voto de los productores de acuerdo con la leche remitida. ${ }^{77} \mathrm{El}$ voto variaba de acuerdo con las cuotas: un voto hasta 400 litros diarios, dos votos los poseedores de cuotas entre 400 y 700 litros y tres votos los que excedieran esta cantidad.

Junto al directorio en el acto eleccionario se debía elegir la Asamblea de Productores constituida por 29 delegados. ${ }^{78}$ A su vez instituía la figura

${ }^{72}$ Ley 9526 , art. $1^{\circ}$.

${ }^{73}$ Ibid., art. $2^{\circ}$.

${ }^{74}$ Se indicaba las industrias a expropiar: las Usinas de Higienización y Pasteurización Cooperativas de Lecherías, S. A., Lechería Central Uruguaya Kasdorf, S. A., Mercado Cooperativo, S. A., La Palma, S. A., La Nena, Alianza de Tamberos y Lecheros La Unión. Ibid., art. $4^{\circ}$.

${ }^{75}$ Ejemplo de esto es que la CONAPROLE continuó produciendo leche chocolatada con el nombre de una de las empresas anteriores como la Cooperativa de Leche, S. A.

${ }^{76}$ Sin embargo, para ser director no era necesario ser productor de leche. Ley 9526, art. 19.

${ }^{77}$ Ibid., art. 18.

${ }^{78} \mathrm{Ibid}$., art. 25. 
de un síndico nombrado por el Banco de la República Oriental del Uruguay como responsable de la fiscalización. ${ }^{79}$

También podemos ver reflejada la intervención en la fijación de precios máximos y mínimos de la leche ${ }^{80}$ así como cierta cuota destinada a los Servicios de Salud Pública y al Consejo del Niño. ${ }^{81}$

\section{Los resultados}

Para evaluar los resultados de la CONAPROLE debemos considerar los objetivos propuestos para la creación de la cooperativa. En primer lugar, conviene examinar sus resultados en términos de la salud pública. ¿Fue la CONAPROLE un factor para la disminución de la mortalidad infantil tal como se cree habitualmente ${ }^{82}$ Las enfermedades gastrointestinales continuaron siendo la principal causa de mortalidad infantil hasta mediados del siglo XX: recién después de 1943 se produce un importante descenso de la tasa de mortalidad por diarrea ${ }^{83} \mathrm{~A}$ pesar de los avances en términos de la calidad de la leche en Montevideo con la creación de la CONAPROLE, la literatura médica de la época explica dicho descenso de mediados de la década de 1940 por las importantes mejoras en lo que respecta a los servicios de prevención y asistencia médicas. ${ }^{84}$ Pero, tal vez, el factor más importante sea la existencia de campañas médicas específicas contra la diarrea infantil de verano implementadas en esos años. ${ }^{8}$

Sin embargo, en términos del "problema lechero" la creación de la CONAPROLE es todo un éxito. Esto se puede constatar con el aumento del consumo de leche pasteurizada en Montevideo que pasó de 76 litros anuales per cápita en 1936 a 155 litros en $1949 .{ }^{86}$ Esto en el marco de la mayor demanda de alimentos de una población en crecimiento y una industria en expansión. ${ }^{87}$ Además, entre 1936 y 1946 la cooperativa desplaza a los

${ }^{79}$ Ibid., art. 23.

${ }^{80} \mathrm{Ibid}$., arts. $6^{\circ}-7^{\circ}$.

${ }^{81}$ Ibid., art. $3^{\circ}$.

${ }^{82} \mathrm{Al}$ respecto véase nota 40.

${ }^{83}$ Birn, Cabella y Pollero, "Enigma", 2006.

${ }^{84}$ Entre las medidas se destacan: la mejora en los servicios de profilaxis, expansión de los centros materno-infantiles, prolongación de los horarios de las policlínicas pediátricas, creación de un servicio pediátrico de urgencia, la gestión cumplida por las visitadoras sociales contribuyendo a la asistencia precoz y orientación de la madre del lactante enfermo.

${ }^{85}$ Birn, Cabella y Pollero, "Infant", 2010.

${ }^{86}$ En 1944, la CONAPROLE producía 83\% de la leche consumida en Montevideo, lo que refleja su importancia económica sectorial. CONAPROLE, "La gestión de CONAPROLE", 1952, citado por Bertino y Tajam, "Agroindustria", 2000.

${ }^{87}$ Robertt, "Reestruturação" 2006, p. 106. 
pequeños tambos que abastecían la capital, creciendo el consumo en 65\% (véase cuadro 1). ${ }^{88}$

Con la creación de la CONAPROLE se solucionó el abastecimiento de leche fresca de buena calidad para Montevideo, superando las dificultades estacionales de la producción y asegurando la rentabilidad de los productores. También se puede señalar como un logro vinculado a la creación de la CONAPROLE el ser capaz de abastecer el mercado interno con una empresa propiedad de los productores, impidiendo que, como sucediera en otros países latinoamericanos, este mercado fuera captado por las transnacionales. ${ }^{89}$

No obstante, la tecnificación posterior de las etapas de producción, almacenaje y transporte fue lenta. No hubo cambios sustanciales en la tecnología lechera (alimentación, manejo, sanidad) y la productividad fue baja. El cuadro 2 muestra que si bien la producción se sextuplicó en 25 años, el área ocupada de la lechería se triplicó, y la productividad, sin importar cómo se la mida, cayó.

El régimen legal de la CONAPROLE fue modificado por otras tres leyes posteriores. En primer lugar, la Ley 10707 del 9 de enero de 1946 reguló la ampliación y funcionamiento de la cooperativa y aumentó el número de directores con un representante del gobierno nacional y otro del gobierno municipal..$^{90}$ La ley también amplió la actuación de la cooperativa e incentivó el ingreso de productores de todo el país. ${ }^{91}$ También extendió la protección estatal facilitando el crédito para inversiones en maquinaria y nuevas plantas de pasteurización en el interior del país. Incluso estableció que $30 \%$ de los excedentes de la industrialización de leche serían destinados a beneficios para el personal. ${ }^{92}$

En segundo lugar, el gobierno municipal de Montevideo puso fin al monopolio en 1982, y el Decreto-Ley 15640 del 4 de octubre de 1984 estimuló la competencia al establecer el régimen de abastecimiento de leche pasteurizada en todo el territorio nacional. Esta ley, al disponer un mínimo de procesamiento de las plantas industriales procesadoras de leche, habilitó el ingreso de empresas multinacionales en el marco de la apertura económica que llevaba adelante el gobierno militar de la época. ${ }^{93}$

${ }^{88} \mathrm{Jacob}$, Breve, 1981.

${ }^{89}$ Terra, Proceso, 1984, p. 128.

${ }^{90}$ Ley 10707 , art. 12.

${ }^{91}$ Ibid., art. $1^{\circ}$.

${ }^{92}$ Esto se enmarca en la política neobatllista, en referencia al gobierno de Luis Batlle Berres (18971964). La nueva situación de prosperidad a partir de la década de 1940 permite la consolidación de un Estado de bienestar influenciado por la matriz batllista original y una cultura política estatista.

${ }_{93}$ Decreto-Ley 15640 , art. $2^{\circ}$. El resultado fue que Parmalat se instala en Uruguay en la década de 1990, al igual que Danone y Nestlé, pero estas se limitan a la fabricación de algunos derivados lácteos. Pero también se "abrió" el mercado montevideano para las plantas elaboradoras del interior del país. 


\section{CUADRO 1. EVOLUCIÓN DEL CONSUMO \\ DE LECHE EN MONTEVIDEO}

\begin{tabular}{lccc}
\hline Año & $\begin{array}{c}\text { Leche } \\
\text { (litros) }\end{array}$ & $\begin{array}{c}\text { Población de } \\
\text { Montevideo }\end{array}$ & $\begin{array}{c}\text { Consumo de leche } \\
\text { per cápita (litros) }\end{array}$ \\
$1936-1937$ & 53407463 & 699040 & 76 \\
$1946-1947$ & 88184464 & 858059 & 103 \\
1949 & 141918277 & 917691 & 155 \\
$1960-1961$ & 166272704 & 1198090 & 139 \\
\hline
\end{tabular}

Fuentes: elaboración propia con base en Supervielle, CONAPROLE, 1986, y Cabella y Pollero, "Estimaciones", 2000.

\section{CUADRO 2. EVOLUCIÓN DE LA PRODUCCIÓN \\ DE LA CONAPROLE $(1936=100)$}

\begin{tabular}{lrrr}
\hline & 1936 & 1952 & 1961 \\
& & & \\
Producción total & 100 & 538.9 & 638.9 \\
Área ocupada & 100 & 329.3 & 365.9 \\
Producción/vaca masa & 100 & 94.3 & 91.3 \\
Producción/litros/hectáreas & 100 & 93.4 & 99.9 \\
Producción/hombre ocupado & 100 & 99.9 & 96.6 \\
Número de remitentes de la CONAPROLE & 100 & 276.9 & s. d. \\
\end{tabular}

Fuente: Elaboración propia con base en CONAPROLE, "Plan de Desarrollo Industrial 1962", mimeo., en Instituto, Cuenca, 1968.

Por último, la Ley 17243, del 29 junio de 2000, incluyó una sección sobre la CONAPROLE. Allí se eliminaron los representantes del Estado en el directorio y el cargo del síndico del Banco de la República Oriental del Uruguay que cumplía funciones de fiscalización de la empresa. También se eliminó la obligación de destinar parte de los excedentes a beneficio de los empleados y la obligación a rendir cuentas al Estado, debiendo hacerlo solamente a la Asamblea de Productores. ${ }^{94}$

${ }^{94}$ La ley de creación de la CONAPROLE y sus posteriores modificaciones pueden leerse como un buen ejemplo de la construcción del Estado de bienestar y el posterior avance de las políticas 


\section{A MODO DE CONCLUSIÓN}

Frente a problemas relacionados con la salud pública y la situación de los productores lecheros, y para solucionar la cuestión del abastecimiento de leche de buena calidad a la ciudad de Montevideo, el Estado uruguayo se decidió por la creación de una cooperativa. Entre las distintas alternativas que se presentaban, se eligió la cooperativa, con lo cual el Estado optó por evadir las reglas del mercado y crear una organización que controlara la producción, centralizara la higienización y asegurara el cumplimiento de los precios. ${ }^{95}$

La opción por la cooperativa era coherente con las concepciones del gobierno de la época. Para este, la intervención del Estado debía limitarse a vigilar y controlar sin ser intervencionista. Esta postura se inscribe en el nuevo escenario generado a partir del golpe de Estado de Terra, que abre una nueva fase del Estado social en Uruguay. La orientación del nuevo gobierno, plasmada en la Constitución de 1934, representa una mezcla de liberalismo, corporativismo y estatalismo. ${ }^{96}$

Sin embargo, se creó una cooperativa de naturaleza particular. La calidad cooperativa de la CONAPROLE ha sido muy debatida. ${ }^{97}$ Las críticas apuntan a las limitaciones de competencia de la asamblea, a que los directores no tienen por qué ser productores, a las diferencias entre socios según los litros que remiten, a que las de "cuotas de leche" se pueden comercializar. ${ }^{98}$ Aunque generalmente se concluye que no se trata de una cooperativa en sentido estricto del término, sino de una régie cooperative. ${ }^{99}$

Retomando la argumentación del comienzo respecto del vínculo entre la forma de surgimiento y los modelos de gestión, podemos sostener que el particular modelo de gestión que asume la CONAPROLE se relaciona con su forma de surgimiento. La política pública que da lugar a la creación de la ConAPRole -la Ley 9526- va de la mano con los reclamos del gremialismo lechero lo que tendrá importantes consecuencias en su desarrollo hasta el día de hoy.

En primer lugar, esto se ve reflejado en la gobernanza. La cooperativa es administrada por un directorio compuesto por productores. La cantidad

liberalizadoras en Uruguay. Una discusión interesante al respecto la plantea Robertt, "Reestruturação", 2006, pp. 114 y ss.

${ }^{95}$ Jacob, Uruguay, 1981, p. 227.

${ }_{96}$ A diferencia del batllismo el nuevo régimen favoreció las políticas de cuño corporativo. Filgueira, "Estado", 1994, pp. 31 y 34.

${ }^{97}$ Véase por ejemplo Bertullo et al., "Cooperativismo", 2004.

${ }^{98}$ Terra, Proceso, 1984, p. 129.

${ }^{99}$ Véanse al respecto Terra, Proceso, 1984, y Reyes, "Antecedentes", 2009. También podríamos preguntarnos si su éxito y longevidad obedecen a esta peculiar forma de organización, pero esto ya forma parte de la futura agenda de investigación. 
de votos de los productores es acorde a la cantidad de leche remitida. Junto con la elección del directorio se elige una Asamblea de Productores con funciones de asesoramiento y consulta y que puede censurar al directorio. Por otra parte, este origen de la cooperativa va a determinar la primacía de lo agrario sobre lo industrial y sobre lo financiero. Las plantas procesadoras de leche instaladas anteriormente veían la leche como un insumo para la agroindustria, en tanto la CONAPROLE vio el proceso industrial como una prolongación de la producción agraria. Esto tendrá consecuencias en la lógica del precio y en la incorporación de tecnología. Mientras el industrial hace fluctuar el precio de acuerdo con la oferta y la demanda, a los productores -así como al Estado- les interesa la estabilidad del precio de manera de asegurarse una ganancia durante todos los meses del año. ${ }^{100}$

También trae consecuencias sobre la incorporación de tecnología. La tecnología de la CONAPROLE se mantuvo prácticamente incambiada por años. Recién en 1948 se ve la necesidad de renovar el equipamiento para la pasteurización y el envasado de la leche. Lo mismo sucedió con los productos elaborados; se mantuvo la gama de productos prácticamente hasta la pérdida del monopolio y no se buscó mejorar su presentación. ${ }^{101}$

Finalmente, sin duda, a través de la iniciativa de la creación de la CONAPROLE, el Estado buscaba mejorar la calidad de la leche consumida por los montevideanos; sin embargo, por sobre este objetivo se determina una primacía de los productores sobre los consumidores que se refleja actualmente, cuando los portavoces de la organización sostienen que maximizar los ingresos de los productores es la razón de ser de la CONAPROLE. ${ }^{102}$

\section{Fuentes CONSULTADAS}

\section{Hemerografía}

Diario de Sesiones de la Cámara de Representantes de la República Oriental del Uruguay, Sesiones ordinarias de la XXXII Legislatura, 2do. periodo, Montevideo, Imprenta Nacional, octubre-diciembre de 1935.

Diario de Sesiones de la Cámara de Senadores de la República Oriental del Uruguay, Sesiones ordinarias de la XXXII Legislatura, 2do. periodo, Montevideo, Imprenta Nacional, diciembre de 1935 .

${ }^{100}$ Una interesante discusión al respecto se puede encontrar en Supervielle, CONAPROLE, 1986.

${ }^{101}$ Ibid.

${ }^{102}$ Tal como argumentaba el presidente de la ConaProle: "El objetivo de maximizar el precio al productor es la razón de ser de CONAPROLE. Es la meta y el único objetivo". "El objetivo", 2006, pp. 4-5. 


\section{Bibliografía}

Alianza Cooperativa Internacional, Declaración de identidad cooperativa, Manchester, II Asamblea General de la Alianza Cooperativa Internacional, 1995.

Battaglia, Filippo, L'organizzazione nelle cooperative, Roma, Edizioni Pigreco, 2004.

Bertino, Magdalena y HÉctor Tajam, "La agroindustria láctea en el Uruguay (19111943)", Montevideo, Universidad de la República, 2000 (Documento de Trabajo $4 / 00)$.

BÉRTOLA, LuIs, La industria manufacturera uruguaya, 1913-196, Uruguay, Centro Interdisciplinario de Estudios sobre el Desarrollo, 1991.

Bertullo, Jorge et al., "El cooperativismo en el Uruguay", Montevideo, Universidad de la República, 2004 (Documento de Trabajo del Rectorado, núm. 22).

Birn, Anne-Emanuelle, Wanda Cabella y Raquel Pollero, "El estancamiento de la mortalidad infantil uruguaya en la primera mitad del siglo XX: análisis por causas de muerte", VII Jornadas Argentinas de Estudios de Población, Tafi del Valle, Universidad Nacional de Tucumán, 2003, 2005, t. I, pp. 137-154.

"El enigma de la mortalidad infantil en Uruguay en la primera mitad del siglo Xx: Un análisis por causas de muerte", trabajo preparado para el taller Lives and Livelihoods: Economic and Demographic Change in Modern Latin America, Ontario, Universidad de Guelph, mayo de 2006, pp. 26-27.

"The Infant Mortality Conundrum in Uruguay during the First Half of the Twentieth Century: an Analysis According to Causes of Death", Continuity and Change, Cambridge University Press, núm. 25, 2010, pp. 435-461.

Bustelo, Francisco, Historia económica: una ciencia en construcción, Madrid, Editorial Síntesis, 1998.

Cabella, Wanda y RaQuel Pollero, "Estimaciones preliminares de población de Montevideo”, Universidad de la República, inédito, 2000.

Camilletti, Alfredo et al., "Cooperativas de trabajo en el Cono Sur. Matrices de surgimiento y modelos de gestión”, Revista UNIRCOOP, Red Universitaria de las Américas en Cooperativismo y Asociativismo, vol. 3, núm. 1, octubre de 2005.

Cravino, Ma. Cristina y Valeria Mutuberría, "Cuando el Estado conforma cooperativas: entre la cooptación y la autonomía” en JuAn P. MARTí y José MA. PÉrez DE URALDE (coords.), La autonomía y la autogestión en las cooperativas. Herramientas y metodologías para su desarrollo, Valencia, Fundación Iberoamericana de Economía Social, 2010, pp. 99-111.

Durán Martínez, Augusto, Naturaleza jurídica de Conaprole, Montevideo, Fundación de Cultura Universitaria, 2003.

"El objetivo de maximizar el precio al productor es la razón de ser de la CONAPROLE. Con el presidente de la Conaprole, Ing. Agr. Jorge Panizza”, Revista El Tambo, Asociación Nacional de Productores de Leche, núm. 152, julio de 2006, Montevideo, pp. 4-5. 
Errandonea, Alfredo y Marcos A. Supervielle, Las cooperativas en el Uruguay. Análisis sociológico del primer relevamiento nacional de entidades cooperativas, Montevideo, Universidad de la República/Confederación Uruguaya de Entidades Cooperativas /Fundación de Cultura Universitaria, 1992.

Filgueira, Fernando, "Un Estado social centenario. El crecimiento hasta el límite del Estado social batllista” en Carlos Filgueira y Fernando Filgueira, El largo adiós al país modelo. Políticas sociales y pobreza en el Uruguay, Montevideo, Arca/ Kellogg Institute, 1994.

Instituto de Economía Agraria, La cuenca lechera de Montevideo, Montevideo, Universidad de la República, 1968.

Instituto NACIONAL DE LA LeChe, "Informe semestral de situación y perspectivas de la lechería uruguaya. Periodo enero-junio 2012”, Montevideo, Área de Información y Estudios Económicos, julio de 2012, <http://www.inale.org/innovaportal/file/1889/1/informe_de_coyuntura_primer_semestre_del_2012-_area_de_ informacion_inale.pdf $>$. [Consulta: 21 de agosto de 2012.]

JaCOb, Raúl, Breve historia de la industria en Uruguay, Montevideo, Fundación de Cultura Uruguaya, 1981.

Uruguay, 1929-1938: Depresión ganadera y desarrollo fabril, Montevideo, Fundación de Cultura Uruguaya, 1981.

El Uruguay de Terra (1931-1938). Una crónica del Terrismo, Montevideo, Banda Oriental, 1983.

LaVergne, Bernard, Le socialisme coopératif, París, PUF, 1955.

L'HARPE, JACQUeS DE, Compendio de agricultura y ganadería, Montevideo, 1934.

Martí, JuAn P., "Cooperativas creadas a partir del Estado. El caso de la ConAProle, una régie cooperative", VII Encuentro del Comité Académico sobre Procesos Cooperativas y Asociativos, Universidad de Santiago de Chile, octubre de 2011.

"Legislación y fomento del cooperativismo en Uruguay. Esfuerzos espasmódicos, fragmentarios y reactivos”, Revista Estudios Cooperativos, vol. 16, núm. 2, Montevideo, diciembre de 2011, pp. 10-26.

Cecilia Soria y Ma. José Dabezies, "Programas públicos para el fomento del cooperativismo de trabajo en Uruguay (1976-2006)" en José MA. PÉrez DE URALDE (coord.), La economía social en Iberoamérica. Enfoques de interés en España, Portugal y Uruguay, Fundación Iberoamericana de Economía Social/Divina Pastora/Confederación Uruguaya de Entidades Cooperativas, Montevideo, 2008, pp. 271-307.

Nahum, Benjamin (coord.), Estadísticas históricas del Uruguay, 1900-1950, t. 1, Montevideo, Universidad de la República, 2007.

Oszlak, Oscar y Guillermo O'Donnell, "Estado y políticas estatales en América Latina: hacia una estrategia de investigación”, Redes, Universidad Nacional de Quilmes, vol. 2, núm. 4, 1995, pp. 99-128. 
Pellegrino, Adela et al., "De una transición a otra: la dinámica demográfica del Uruguay en el siglo XX" en BenJamin NAHUm (ed.), El Uruguay del siglo XX, t. II, La sociedad, Montevideo, Universidad de la República/Banda Oriental, 2008.

República Oriental del Uruguay, Ministerio de Ganadería y Agricultura. Dirección de Agronomía. Sección de Estadística y Economía Agraria, Censo agropecuario, 1937, Montevideo, Editorial Libertad, 1938.

Reyes Lavega, Sergio, "Antecedentes y contenidos de la Ley General de Cooperativas núm. 18407”, Observatorio Iberoamericano del Empleo y la Economía Social y Cooperativa, 2009, 〈http://www.neticoop.org.uy/article2513.html〉. [Consulta: 1 de septiembre de 2011.]

Robertt Niz, Pedro A., "Reestruturação produtiva e social em uma empresa globalizada. O caso da Conaprole no Uruguai”, tesis de doctorado en Sociología, Porto Alegre, Universidade Federal do Rio Grande do Sul, 2006.

Sala de Sesiones de la Cámara de Representantes, Ley 10707, “Conaprole. Se da el régimen para la ampliación y el funcionamiento de la Cooperativa Nacional de Productores de Leche", República Oriental del Uruguay, Poder Legislativo, 9 de enero de 1946, <http://www0.parlamento.gub.uy/leyes/AccesoTextoLey. asp?Ley $=10707 \&$ Anchor $=>$. [Consulta: 1 de agosto de 2011.]

, Ley 17 243, "Servicios públicos y privados, seguridad pública y condiciones en las que se desarrollan las actividades productivas", 29 de junio de 2000, <http:// www0.parlamento.gub.uy/leyes/AccesoTextoLey.asp?Ley=17243\&Anchor $=>$. [Consulta: 1 de agosto de 2011.]

Sala de Sesiones de la Cámara de Senadores, Ley 9526, “Cooperativa Nacional de Productores de Leche”, República Oriental del Uruguay, Poder Legislativo, 14 de diciembre de 1935, <http://www0.parlamento.gub.uy/leyes/AccesoTextoLey. asp? Ley $=09526 \&$ Anchor $=>$. [Consulta: 1 de agosto de 2011.]

Sala de Sesiones del Consejo de Estado, "Decreto-Ley 15640. Leche pasteurizada. Se aprueba el régimen de abastecimiento en todo el territorio nacional", República Oriental del Uruguay, Poder Legislativo, 4 de octubre de 1984, <http://www0. parlamento.gub.uy/leyes/AccesoTextoLey.asp?Ley=15640\&Anchor $=>$. [Consulta: 1 de agosto de 2011.]

Sosa, Sonia, Conaprole: origen y trayectoria, Montevideo, Centro de Investigaciones Económicas, 1986 (Colección Estudios, núm. 26).

Supervielle, Marcos A., Conaprole, Montevideo, folleto, 1986, 78 pp.

Tamayo SÁenz, Manuel, "El análisis de las políticas públicas" en Rafael BañóN y ERnesto CARrillo (comps.), La nueva administración pública, Madrid, Alianza Universidad, 1997.

TARAmasco, MA. P. et al., "Estudio sobre Conaprole. Entrevista a Pedro Olmos. Gerente de Producción de Conaprole”, Montevideo, Universidad de la República, 1997.

Terra, Juan P., Proceso y significado del cooperativismo uruguayo, Montevideo, Comisión Económica para América Latina/Arca, 1984. 
Uruguay XXI Instituto de Promoción de Inversiones y Exportaciones, "Informe de comercio exterior de Uruguay. Año 2011”, Montevideo, República Oriental de Uruguay, 2012, <http://www.uruguayxxi.gub.uy/wp-content/uploads/2011/11/ Informe-de-Comercio-Exterior-de-Uruguay-Diciembre-2011-Uruguay-XXI1. pdf $>$. [Consulta: 21 de agosto de 2012.]

VANEK, Jaroslav, Imprese senza padrone nelle economie di mercato (a cura di B. Giuliani), Roma, Edizioni Lavoro, 1985.

VAras, Augusto, "Democratización y políticas públicas” en Raúl UrZúa (ed.), Cambio social y políticas públicas, Santiago, Universidad de Chile, 1997.

Vicens, Bartolomé, Régimen cooperativo, Montevideo, Palacio del Libro A. Monteverde y Cía., 1941. 